OPEN ACCESS

Edited by:

Yunrong Chai,

Northeastern University, USA

Reviewed by:

Xiuzhu Dong,

Institute of Microbiology (CAS), China

Lyle Whyte,

McGill University, Canada

${ }^{*}$ Correspondence:

Qirong Shen

shenqirong@njau.edu.cn

${ }^{\dagger}$ These authors have contributed equally to this work.

Specialty section:

This article was submitted to

Terrestrial Microbiology,

a section of the journal

Frontiers in Microbiology

Received: 06 July 2016 Accepted: 15 November 2016 Published: 29 November 2016

Citation:

Yuan J, Zhao M, Li R, Huang $Q$ Rensing C, Raza W and Shen $Q$ (2016) Antibacterial

Compounds-Macrolactin Alters the Soil Bacterial Community and Abundance of the Gene Encoding PKS

Front. Microbiol. 7:1904. doi: 10.3389/fmicb.2016.01904

\section{Antibacterial Compounds-Macrolactin Alters the Soil Bacterial Community and Abundance of the Gene Encoding PKS}

\author{
Jun Yuan ${ }^{1 t}$, Mengli Zhao'tt, Rong Li', Qiwei Huang ${ }^{1}$, Christopher Rensing ${ }^{2,3}$, \\ Waseem Raza ${ }^{1}$ and Qirong Shen ${ }^{1 *}$
}

' Jiangsu Provincial Key Lab of Organic Solid Waste Utilization and Jiangsu Collaborative Innovation Center for Organic Solid Waste Utilization - College of Resources and Environmental Sciences, Nanjing Agricultural University, Nanjing, China, ${ }^{2}$ Fujian Provincial Key Laboratory of Soil Environmental Health and Regulation, College of Resources and Environment, Fujian

Agriculture and Forestry University, Fuzhou, China, ${ }^{3} \mathrm{~J}$. Craig Venter Institute, La Jolla, CA, USA

Macrolactin produced by many soil microbes has been shown to be an efficient antibacterial agent against many bacterial pathogens. However, studies examining the effect of macrolactin on both the soil bacterial community and the intrinsic bacterial species that harbor genes responsible for the production of this antibiotic have not been conducted so far. In this study, a mixture of macrolactin was isolated from the liquid culture of Bacillus amyloliquefaciens NJN-6, and applied to the soil once a week for four weeks. 16S rRNA Illumina MiSeq sequencing showed that continuous application of macrolactin reduced the $\alpha$-diversity of the soil bacterial community and thereby changed the relative abundance of microbes at both the phylum and genus level. The relative abundance of Proteobacteria and Firmicutes was significantly increased along with a significant decrease in the relative abundance of Acidobacteria. However, the application of macrolactins had an insignificant effect on the total numbers of bacteria. Further, the native gene responsible for the production of macrolactin, the gene encoding polyketide synthase was reduced in copy number after the application of macrolactin. The results of this study suggested that a bactericide from a microbial source could decrease the diversity of the soil bacterial community and change the bacterial community structure. Moreover, the populations of the intrinsic bacterial species which harbor genes responsible for macrolactin production were inhibited when the external source antibiotic was applied.

Keywords: macrolactin, soil bacterial community, PKS gene, MiSeq sequencing, microbial source antibiotics

\section{INTRODUCTION}

Soil harbors an aggregation of microorganisms containing millions of microbes per gram (Torsvik et al., 1990). These soil microbes play an important role in soil functions such as nutrition cycling, pollutant degradation and mass and energy flow (Bremner and Blackmer, 1978; Lewis et al., 1999; Barros and Feijóo, 2003). In addition, they influence both plant growth and productivity by supporting the production of antibiotics (Bentley et al., 2002; Newman and Cragg, 2012). 
Many reports found that soil microbes are a reservoir for the production of antibiotics, but only a small fraction has so far been discovered and characterized. Macrolide compounds are widely used antibiotics in clinics and display different biological activities including modulating inflammation (Kanoh and Rubin, 2010). Macrolactins are a large group of macrolide antibiotics with a 24-member lactone ring first discovered in a marine Bacillus (Gustafson et al., 1989). Macrolactin showed numerous properties such as inhibiting the proliferation of cancer cells, a protective effect on T-lymphocyte from an HIV infection due to the phosphatase inhibitory activity (Gustafson et al., 1989), anti-inflammatory activity towards colon epithelial cells, and the inhibition of cell division by the reduction of the $\mathrm{H}^{+}$-transporting two-sector ATPase, which is essential for the viability of bacterial cells (Romero-Tabarez et al., 2006; Zotchev et al., 2006; Park et al., 2014). Recently, its biocontrol activity to suppress many bacterial pathogens has been reported (Arguelles-Arias et al., 2009; Chen et al., 2009; Wang et al., 2012; Yuan et al., 2012a).

In the hospital or animal production facilities, the prescribed antibiotics are largely excreted by the recipient after administration (Halling-Sørensen et al., 2002; Thiele-Bruhn et al., 2004), resulting in high levels of antibiotic residues in animal manure or domestic waste water. Once macrolactins and their derivatives are applied along with manure, they tended to appear or even accumulate in the soil. In addition, it has increasingly been reported that macrolactins along with the microbes producing it, are being used to control soil-borne pathogen diseases in agricultural production (Han et al., 2005; Sopheareth et al., 2013; Yuan et al., 2013). Many biomimetic synthetic chemicals are being put into use for this purpose (Garson, 1993; Smith and Ott, 1996; Marino et al., 2002), thereby artificially increasing the concentration of macrolactin in soil. Macrolactin have an abroad-spectrum antibacterial activity against soil bacteria. There are many reports that antibiotics in soil can change the soil microbial community structure, increase the antibiotic resistance of soil microbes, and alter the original soil ecological function (Schmitt et al., 2004; Negreanu et al., 2012; Reichel et al., 2014; Udikovic-Kolic et al., 2014; Yamamura et al., 2014). However, the effects of macrolactin on the soil bacterial community and soil ecological functions are still only vague. Among the soil ecological functions, pathogen suppression is important for healthy plant growth, and antibiotic producing genes may be responses for soil pathogen suppression (Mendes et al., 2011). Macrolactin is synthesized by the polyketide synthase (PKS) (Schneider et al., 2007; Chen et al., 2009), and here the ketosynthase domain is most important for function (Schneider et al., 2007; Owen et al., 2013). In consideration of the antibacterial activity and the plant-induced elicitation of macrolactin in systemic resistance, the PKS gene may play a key role in the pathogen suppressive character of soil. However, there is only limited knowledge on the possible mechanisms of how the abundance of genes encoding PKS in soil could be altered when an excess of their respective gene products are suddenly supplied to the soil.

In our previous study, we isolated three macrolactin compounds (macrolactin A, 7-O-malonyl macrolactin A, and 7-O-succinyl macrolactin A) from the plant growth promoting rhizobacterium Bacillus amyloliquefaciens strain NJN-6 and these compounds displayed strong antibacterial activity, but very weak antifungal activity (Yuan et al., 2012a, 2014). In this study, we extracted a mixture of these three macrolactins and added them to the soil in vitro. Illumina MiSeq sequencing of the $16 \mathrm{~S}$ rRNA gene region was performed to analyze changes in the soil bacterial community, and quantitative real-time PCR was used to evaluate variation in the abundance of the genes encoding PKS after exposure to macrolactins.

\section{MATERIALS AND METHODS}

\section{Isolation of Macrolactin Compounds}

The antimicrobial compounds were isolated after the fermentation of strain NJN-6, which was isolated from the banana rhizosphere and identified as B. amyloliquefaciens by $16 \mathrm{~S}$ rRNA sequencing (Yuan et al., 2012b).

For macrolactin isolation, strain NJN-6 was incubated in LB medium (10 g of tryptone, $5 \mathrm{~g}$ of yeast extract, and $10 \mathrm{~g}$ of $\mathrm{NaCl}$ per liter). For the production of antagonistic substances, the NJN-6 strain was grown in 1 L Erlenmeyer flasks with a $200 \mathrm{~mL}$ working volume, at $37^{\circ} \mathrm{C}$ and $170 \mathrm{rpm}$ for $60 \mathrm{~h}$. After wards the cell-free supernatant was collected by centrifugation at $12000 \mathrm{~g}\left(4^{\circ} \mathrm{C}\right)$ for $10 \mathrm{~min}$. Then an Amberlite XAD-16 (Alfa Aesar, a Johnson Matthey Company, Ward Hill, MA, USA) column (10 g) was used to absorb the active compounds. To remove the impurities, the column was first washed with $150 \mathrm{~mL}$ deionized water followed by $50 \mathrm{~mL} 30 \%$ methanol. The macrolactins were finally eluted with $100 \%$ methanol. The collected eluted fraction was concentrated by a rotary evaporator to remove the methanol. For further purification, the liquid was adjusted to $\mathrm{pH} 2.0$ with $6 \mathrm{M} \mathrm{HCl}$ and stored at $4^{\circ} \mathrm{C}$ overnight. The precipitates were removed by centrifugation at $12000 \mathrm{~g}\left(4^{\circ} \mathrm{C}\right)$ for $10 \mathrm{~min}$, and the supernatants were readjusted to $\mathrm{pH} 7.0$ with $6 \mathrm{M} \mathrm{NaOH}$. The obtained solution was then freeze-dried into powder and re-solved in deionized water.

\section{Detection of Macrolactins by HPLC}

HPLC was performed using a HPLC 1200 device (1200 series, Agilent, Santa Clara, CA, USA) to analyze macrolactins. For analysis, a $5 \mu \mathrm{L}$ sample was injected into the HPLC column (Eclipse XDB-C18, $4.6 \mathrm{~mm} \times 250 \mathrm{~mm}, 5 \mu \mathrm{m}$, Agilent, Santa Clara, CA, USA). The conditions were set up as described in our previous study (Yuan et al., 2012a). Briefly, the column temperature was maintained at $20^{\circ} \mathrm{C}$ throughout the analysis; the mobile phase was the solvent containing $60 \% \mathrm{~A}(0.1 \%(\mathrm{v} / \mathrm{v})$ $\left.\mathrm{CH}_{3} \mathrm{COOH}\right)$ and $40 \% \mathrm{~B}\left(\mathrm{CH}_{3} \mathrm{CN}\right)$ at a flow rate of $0.6 \mathrm{~mL} / \mathrm{min}$; and an ultraviolet (UV) detector was used to detect peaks at $230 \mathrm{~nm}$. There is no commercial standard sample for sale. The standard sample was obtained using high-speed countercurrent chromatography (HSCCC) method reported previously (He et al., 2012, 2013). The concentration of macrolactins in the collected solution was quantified to be $38.6 \mathrm{mg} / \mathrm{L}$. 


\section{Soil Treatment with Macrolactins In Vitro}

The soil was collected from an experimental site at "Wan Zhong" orchard $\left(18^{\circ} 230^{\prime} \mathrm{N}, 108^{\circ} 440^{\prime} \mathrm{E}\right)$, Le Dong County, Hainan Province, China. The experiment was performed in vitro with $15 \mathrm{~g}$ soil placed in a Petri dish with following treatments: (1) Control samples, the soil was amended with $1 \mathrm{ml}$ sterile deionized water weekly; (2) treatment samples, the soil was amended with $1 \mathrm{ml}$ sterile macrolactin solution weekly. Macrolactin solution or water was pipetted to soil lightly and mixed well by vortex. The whole treatment lasted for four weeks. All the Petri dishes were sealed with Parafilm and incubated at $30^{\circ} \mathrm{C}$. Three replicates were performed for each treatment.

\section{Amplification and Sequencing of Bacterial 16S rRNA Genes}

The DNA extracted (using the PowerSoil DNA Isolation Kit, MoBio Laboratories Inc., USA) from each soil sample (0.5 g) after 4 weeks inoculation served as the template for bacterial $16 \mathrm{~S}$ rRNA gene sequence amplification. Three successive DNA extractions of each sample were pooled before performing polymerase chain reaction (to minimize the DNA extraction bias). The DNA quality was assessed according to the 260/280 nm and 260/230 nm absorbance ratios using a NanoDrop ND-2000 spectrophotometer (NanoDrop, ND2000, Thermo Scientific, 111 Wilmington, DE, USA). The concentration of extracted DNA was between $37 \mathrm{ng} / \mu \mathrm{l}$ and $61 \mathrm{ng} / \mu \mathrm{l}$. The 520F (forward primer) and $802 \mathrm{R}$ (reverse primer) primer sets were used for V4 region amplification of the bacterial $16 \mathrm{~S}$ rRNA gene. The primers used for final sequencing consisted of the appropriate Illumina adapter, pad linker, the gene-specific primer and a 6-nt barcode unique for each sample was attached to the reverse primer. The primers and the PCR condition are listed in Supplementary Table S1. PCR amplification was performed under the following conditions: the reaction mix $(25 \mu \mathrm{l})$ contained $10 \mu \mathrm{mol}$ of each primer $(1 \mu \mathrm{l}), 1 \mu \mathrm{l}$ template DNA $(20 \mathrm{ng} / \mu \mathrm{l}), 2.5 \mathrm{mmol}$ of dNTPs $(2 \mu \mathrm{l}), 5 \times$ Q5 reaction buffer $(5 \mu \mathrm{l})$ and $5 \times$ Q5 GC high enhancer $(5 \mu \mathrm{l}), 5 \mathrm{U} / \mu \mathrm{l}$ of Q5 polymerase $(0.25 \mu \mathrm{l})$. After PCR amplification and agarose gel electrophoresis, bands were excised and purified using the MinElute PCR Purification Kit (Qiagen, Germany), separated by electrophoresis through a 1.5\% agarose gel and purified from the gel using the Qiagen QIAquick Gel Extraction kit (Qiagen, Germany). The amplicons was subjected to unidirectional sequencing on the Illumina MiSeq sequencing platform of Personal Biotechnology Co., Ltd (Shanghai, China).

\section{$16 S$ rRNA Sequencing Data Processing and Analysis}

The sequencing data was processed with Mothur v.1.33.3 (Schloss et al., 2009) as described by Kozich et al. (2013). Make.contigs command was used to combine the two sets of reads due to the use of dual-index primers. Reads were screened using screen.seqs and reads that contained more than 0 ambiguous bases or were longer than 275 bp were removed from further analysis. Sequences were aligned to the SILVA bacterial database (Pruesse et al., 2007). Sequences that started and ended at the same position and had no more than 8 homopolymers were retained.
Chimeras were detected using the Mothur implementation of UCHIME (Edgar et al., 2011). Detected chimeras were removed from the further downstream analysis. Sequences were classified using the Bayesian classifier against the Mothur compatible Ribosomal Database Project (RDP) training set version 10 (Wang et al., 2007). Taxonomic classification was based on RDP identification for each operational taxonomic unit (OTU). Sequences that were classified as Chloroplast, Mitochondria, unknown, or Eukaryota were removed from further analysis. An OTU-based approach was performed to calculate the richness and diversity using MOTHUR with an OTU cut-off of 0.03 . The rarefaction curve was created to compare the relative levels of OTU richness across all soil samples. Richness indices of Chao1 and the abundance based on coverage estimator (ACE) were calculated to estimate the number of OTUs that were present in the sampling assemblage. The diversity within each individual sample was estimated using the nonparametric Shannon diversity index. The evenness of each individual sample was calculated based on the Shannon diversity index.

A multivariate data analysis was performed by using METAGENassist a web server tool (Arndt et al., 2012) that assigns probable microbial functions based on 16S rRNA data. In addition, principal component analysis (PCA) based on all taxa composition and relative abundance was conducted using the METAGENassist to better compare bacterial community similarities. SAS (ver. 9.3; SAS Institute) was used for statistical analyses. To determine statistical differences between treatments two-way ANOVA analysis with a Tukey post-hoc adjustment was used on $\log 2$ transformed data using the PROC MIXED function.

\section{Real-Time PCR for Genes Encoding PKS and 16S rRNA Genes}

To generate external standard curves for real-time PCR assays, the microbial 16S rRNA and PKS were PCR-amplified from extracted DNA of Bacillus amyloliquefaciens NJN-6 with each pair of primers (listed in Supplementary Table S1), respectively. The PCR products were gel-purified using the Axygen gel extraction Kit (Axygen, Union City, CA, USA), cloned into pMD19-T vector and transformed into competent Escherichia coli Top 10 cells (Invitrogen, Carlsbad, CA, USA). The positive clones were selected and verified by re-amplification using the vector-specific primers T3 and T7, and further verified by DNA sequencing. Then, the insert clone of each target gene was selected to extract plasmid DNA with the Axygen Plasmid Miniprep Kit (Axygen, Union City, CA, USA). The plasmid DNA concentration was determined on a NanoDrop ND-2000 spectrophotometer (NanoDrop, Wilmington, DE, USA) and the copy numbers of each target gene was calculated directly from the concentration of the extracted plasmid DNA, respectively. Tenfold serial dilutions of a known copy number of the plasmid DNA were subjected to real-time PCR assay in triplicate to generate an external calibration curve. Amplification efficiencies with $R^{2}$ values for $16 \mathrm{~S}$ rRNA and PKs were 0.996 and 0.9994 , respectively.

Real-time PCR was performed in biological triplicates and each involved three technical replicates with two negative controls on the Applied Biosystem 7500 Real-Time PCR System 
(ABI, USA) to enumerate the abundance of all the genes described above using SYBR Premix Ex Taq ${ }^{\text {TM }}$ (Tli RnaseH Plus) (TaKaRa Biotechnology Co., Ltd). The reaction mixture contained $10 \mu \mathrm{l}$ SYBR Premix Ex Taq ${ }^{\mathrm{TM}}(2 \times), 0.4 \mu \mathrm{l}$ of each primer (10 pmol/ $\mu \mathrm{l}), 0.4 \mu \mathrm{l}$ ROX Reference Dye II, and $1 \mu \mathrm{l}$ of template DNA $(20 \mathrm{ng} / \mu \mathrm{l})$ with a final volume of $20 \mu \mathrm{l}$. The primer sets and thermal conditions are listed in Supplementary Table S1. After the real-time PCR assay, the specificity of the amplification was verified by melting-curve analysis and agarose gel electrophoresis.

\section{RESULTS}

\section{Isolation of Macrolactins from NJN-6 Strain}

To obtain macrolactins, resin absorbtion coupled with acid precipitation was used to remove the lipopeptide type impurities. A total of $50 \mathrm{ml}$ concentrated solution was prepared from $8 \mathrm{~L}$ culture medium of the strain NJN-6. Three main peaks were detected in HPLC chromatography (Supplementary Figure $\mathrm{S} 1$ ), and then identified to be macrolactin A, 7-O-malonyl macrolactin A, and 7-O-succinyl macrolactin A when comparing the retention time with our previous results (Yuan et al., 2012a). The total concentration of macrolactins in the purified solution was $38.6 \mathrm{mg} / \mathrm{L}$. The concentration of macrolactins in the soil (15 g) after application was calculated to be $2.57 \mu \mathrm{g} / \mathrm{g}$ for one time, and the total concentration after four applications was $10.29 \mu \mathrm{g} / \mathrm{g}$.

\section{Effect of Macrolactin on the Soil Bacterial Community Composition}

A total of 232,559 sequences and 36,303-43,040 sequences per sample ( mean $=38,760$ ) were clustered to 18,808 OTUs using the average neighbor algorithm with a cut-off at $97 \%$ similarity. The raw sequence data have been deposited into the NCBI Sequence Read Archive (SRA) as study ID SRR4289338, SRR4292627, SRR4292629, SRR4292630, SRR4292631, and SRR4292670. Out of the total, $87.07 \%$ sequences could be classified at the phylum level, and $58.05 \%$ sequences could be classified to the genus level. When the OTUs were classified into phylotypes, the most abundant phyla were Acidobacteria, Actinobacteria, Proteobacteria, Verrucomicrobia, and unclassified groups, and these taxa accounted for more than $95 \%$ of the total sequences of both the macrolactin treatment and the control soil samples (Figure 1). In terms of phylum level changes after the addition of the macrolactins, the relative abundance of Acidobacteria, Actinobacteria, Verrucomicrobia, and unclassified groups was significantly decreased from $24.2 \%, 19.7 \%, 4.9 \%$, and $18.0 \%$ to $8.9 \%, 8.8 \%, 3.3 \%$, and $7.4 \%$, respectively (Figure 1). Protebacteria the most abundant group was significantly increased from 28.8 to $68.3 \%$ when exposed to macrolactins (Figure 1). In addition, the Firmicutes were also found to be in more relative abundance in the macrolactin treated soil sample (from 0.47 to $0.94 \%$ ).

We further analyzed at the genus level, and focused on the groups with a relative abundance higher than $1 \%$ in

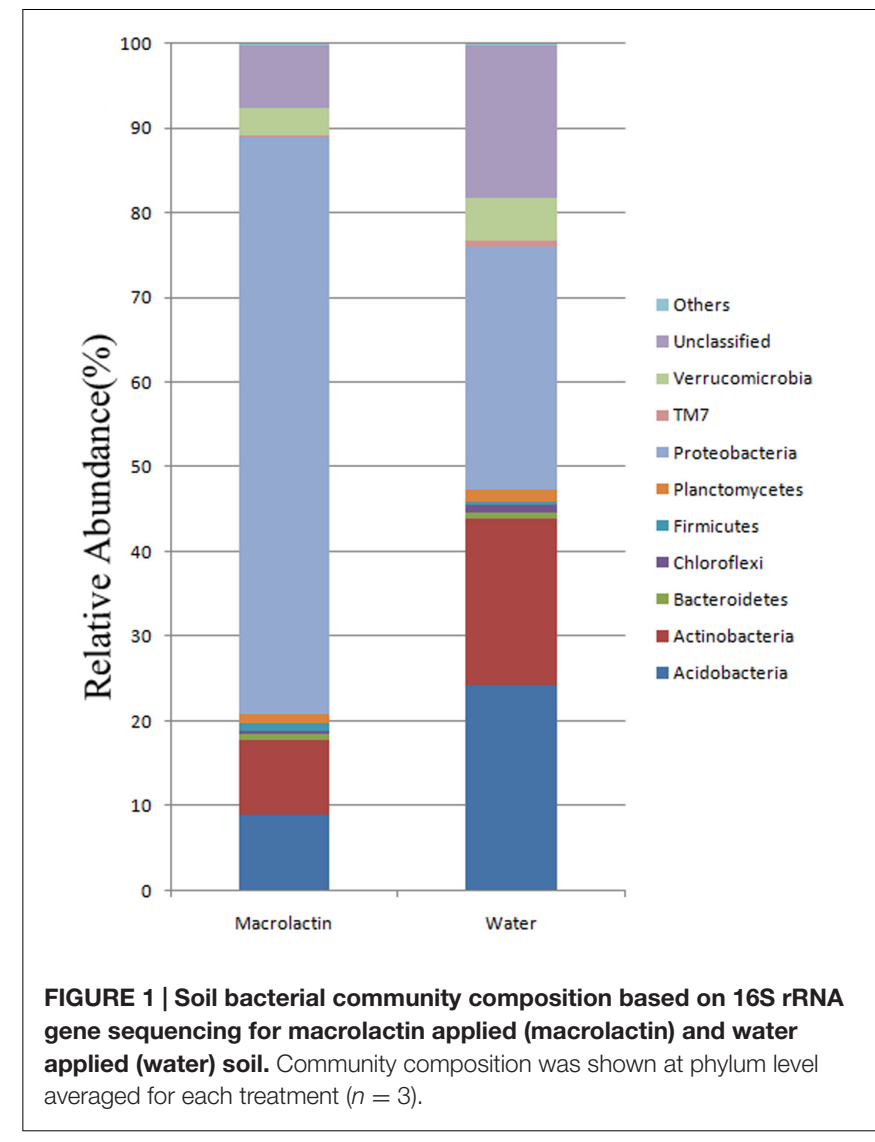

either one or both treatments. The results are listed in the Table 1. The relative abundance of genera Gp1, Gp2, Gp3, Gp13, Marmoricola, Nocardioides, Phenylobacterium, Skermanella, and Spartobacteria_genera_incertae_sedis was significantly higher

TABLE 1 | Frequency of the most abundant ( $>1 \%$ ) classified bacterial genera (expressed as \%) of all classified sequences within macrolactin treated soil and water control soil.

\begin{tabular}{llrr}
\hline Phylum & Genus & Macrolactin & \multicolumn{1}{c}{ Control } \\
\hline Acidobacteria & Gp1 & $4.60 \pm 0.59 \mathrm{~b}$ & $11.64 \pm 1.37 \mathrm{a}$ \\
& Gp13 & $0.45 \pm 0.14 \mathrm{~b}$ & $2.03 \pm 0.48 \mathrm{a}$ \\
& Gp2 & $1.68 \pm 0.27 \mathrm{~b}$ & $6.74 \pm 1.07 \mathrm{a}$ \\
Actinobacteria & Gp3 & $1.47 \pm 0.20 \mathrm{~b}$ & $3.05 \pm 0.27 \mathrm{a}$ \\
& Narmoricola & $0.07 \pm 0.01 \mathrm{~b}$ & $1.53 \pm 0.22 \mathrm{a}$ \\
Proteobacteria & Burkholderia & $14.30 \pm 4.33 \mathrm{a}$ & $1.94 \pm 0.57 \mathrm{~b}$ \\
& Dyella & $1.17 \pm 0.64 \mathrm{a}$ & $0.06 \pm 0.01 \mathrm{~b}$ \\
& Phenylobacterium & $0.54 \pm 0.13 \mathrm{~b}$ & $1.23 \pm 0.34 \mathrm{a}$ \\
& Rhodanobacter & $33.56 \pm 7.02 \mathrm{a}$ & $3.25 \pm 0.55 \mathrm{~b}$ \\
& Skermanella & $0.93 \pm 0.15 \mathrm{~b}$ & $2.17 \pm 0.40 \mathrm{a}$ \\
Verrucomicrobia & Spartobacteria_ & $1.58 \pm 0.14 \mathrm{~b}$ & $2.80 \pm 0.50 \mathrm{a}$ \\
& genera_incertae_sedis & &
\end{tabular}

The different letters "a" and "b" here used for the marker of statistically significant difference $(p<0.05)$, if there is significant difference between macrolactin treatment and water control, they are marked as " $a$ " and " $b$ " separately, if not, they are both marked as "a". Data show a mean $\pm S D(n=3)$. 
TABLE $2 \mid \alpha$-diversity indexes of soil microbial community in both macrolactin treated soil and water control soil evaluated by 16 S rRNA gene sequencing.

\begin{tabular}{ccccc}
\hline & Chao & ACE & Shannoneven & Shannon \\
\hline Macrolactin & $10080 \pm 734 \mathrm{~b}$ & $19066 \pm 938 \mathrm{~b}$ & $0.57 \pm 0.05 \mathrm{~b}$ & $4.68 \pm 0.44 \mathrm{~b}$ \\
Water & $12087 \pm 531 \mathrm{a}$ & $22161 \pm 1178 \mathrm{a}$ & $0.73 \pm 0.01 \mathrm{a}$ & $6.03 \pm 0.08 \mathrm{a}$
\end{tabular}

The different letters "a" and "b" here used for the marker of statistically significant difference $(p<0.05)$, if there is significant difference between macrolactin treatment and water control, they are marked as "a" and "b" separately, if not, they are both marked as "a". Data show a mean $\pm S D(n=3)$.

in the control soil sample than those in the macrolactins treated soil sample; while the relative abundance of the genera Burkholderia and Dyella was significantly increased after macrolactins application. Surprising results were obtained for the genus Rhodanobacter, whose relative abundance was promoted by macrolactins from 3.25 to $33.56 \%$.

\section{Changes of the Soil Bacterial Community Structure by Macrolactins}

The rarefaction curve was firstly made at $97 \%$ similarity to reveal the increase of OTU numbers with the sequencing depth. The higher OTU number was observed in the control soil sample (water) compared to the macrolactins treated soil sample (macrolactin) (Supplementary Figure S2), which indicated that the macrolactins decreased the bacterial diversity when applied into the soil. Then we analyzed the $\alpha$-diversity of the community structure to evaluate the effect of macrolactins on the soil bacterial community (Table 2). All the chosen parameters of $\alpha$-diversity indices were significantly decreased by the macrolactins application, indicating the reduction of richness, diversity and evenness of the soil bacterial community.

Hierarchical cluster analysis of the similarity of bacterial communities in this study confirmed that macrolactins application could significantly changed the bacterial community structure when compared to the control (Figure 2A). Furthermore, the PCA based on the abundance of all taxa showed the distance differences in the composition of the bacterial community in both the control and the macrolactins treated soil samples (Figure 2B).

\section{Influence of Macrolactins on the Abundance of 16S rRNA and PKS Gene}

The quantitative real-time PCR data demonstrated that the copy number of the PKS gene was significantly reduced by the application of macrolactins when compared to the control (Table 3). However, the soil bacterial 16S rRNA gene abundance was decreased with no significant difference after the macrolactins application (Table 3).

\section{Macrolactins Influence the Potential Metabolic Function of Soil Microbial Community}

In order to predict the potential functions of the soil microbial community, we assigned the OTUs from taxonomic to metabolic function using the METAGENassist webserver tool. The heatmap analysis of the metabolic activities showed the differences between control and macrolactins treatment based on the Jensen-Shannon distance. The abundance of the genetic information encoding four bacterial metabolic pathways in soil (lignin degrader, nitrite reducer, sulfur oxidizer, and cellulose degrader) was elevated; while the abundance of other six metabolic pathways (chitin degradation, sulfide oxidizer, dehalogenation, xylan degrader, ammonia oxidizer, and sulfate reducer) was reduced by the application of macrolactins (Figure 3).

\section{DISCUSSION}

Macrolactins is a group of effective antimicrobial compounds, which are reported to show many clinically important biological activities, such as anti-cancer, anti-Staphylococcus aureus, and antiviral activities (Romero-Tabarez et al., 2006; Park et al., 2014). Recently, with the development of biocontrol applications for crop diseases, macrolactins were also found to be an effective biocontrol agent reported to antagonize many bacterial plant pathogens and played the main role in suppressing crop diseases (Jaruchoktaweechai et al., 2000; Romero-Tabarez et al., 2006; Chen et al., 2009). In our previous study, macrolactins were proven to be an antimicrobial agent to suppress the growth of Ralstonia solanacearum (Yuan et al., 2012a). In this study, many groups such as Acidobacteria and Actinobacteria were lower in abundance in the macrolactins treated soil sample compared to the control soil sample (Figure 1; Table 1), which again indicated a broad-spectrum antibacterial activity of macrolactins. A broadspectrum antimicrobial activity is preferred in disease control as being able to inhibit several pathogens simultaneously. However, this broad-spectrum activity can also lead to major undesired consequences in the soil bacterial community because many nontarget bacteria even beneficial bacteria could also be killed at the same time. In this study, the microbial antibiotic macrolactin displayed a similar disruptive effect on the microbial ecology as do agricultural chemicals (Monard et al., 2011). Some microbial groups were significantly reduced in relative abundance and other groups were significantly increased, while the total numbers of bacteria were not changed significantly as revealed by the qPCR analysis of $16 \mathrm{~S}$ rRNA copy numbers after 4 weeks treatment. This might be due to sensitive groups being inhibited by macrolactins, while the resistant groups outgrew other groups due to fewer competitors.

When the effect of macrolactins on the soil bacterial community structure was taken into account, these compounds significantly reduced the bacterial diversity and richness (Table 2). The relative abundance of almost all the phyla except Proteobacteria and Firmicutes, was reduced (Figure 1), suggesting that the pre-existing balance of the soil bacterial community was disrupted by the addition of macrolactins. Similar reduction in the soil bacterial community and soil activity (enzyme activity) has been reported for the inputs of chemicals (Floch et al., 2011; Monard et al., 2011; Muñoz-Leoz et al., 2011; Jacobsen and Hjelmsø, 2014). At this point, there is no difference between the 


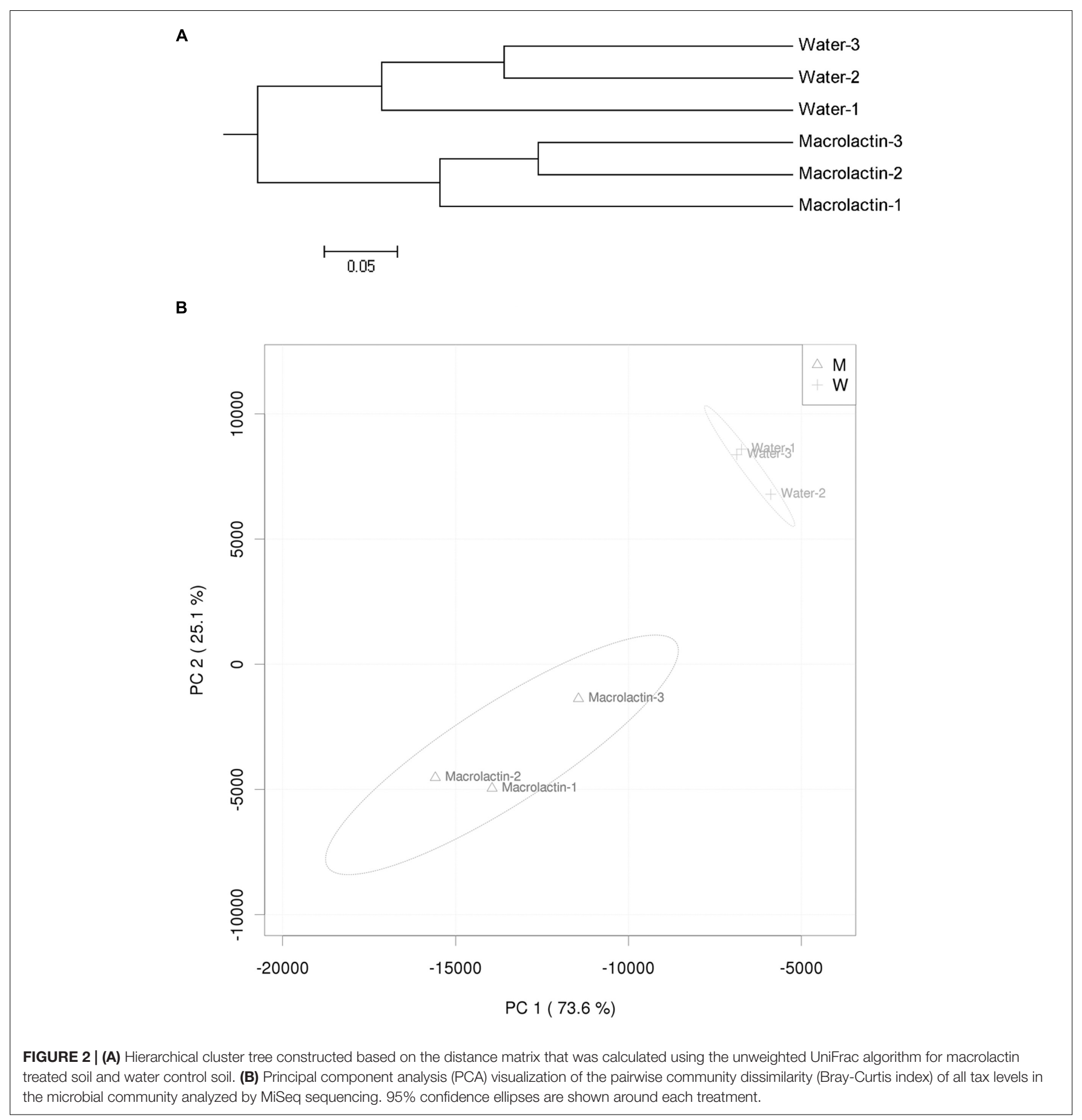

microbial antibiotic and chemically synthesized bactericides. The general taxonomic patterns largely differed between treatment and control soil sample regarding the abundances of major taxonomic groups (Figure 1). It was reported that the abundance of Actinobacteria and Acidobacteria depends on the soil moisture status and pH (Fierer et al., 2012; Barnard et al., 2013), therefore, the soil moisture status in this experiment was strictly controlled every week to rule out variations due to moisture differences. The macrolactins solution was adjusted to $\mathrm{pH} 7$ and therefore there was no difference in $\mathrm{pH}$ between treatment and control soil samples. Although the Actinobacteria phylum was reported to have a high resistance to environmental stress due to its numerous members being Gram-positive with a high $\mathrm{G}+\mathrm{C}$ content (Zviagintsev et al., 2007; Barnard et al., 2013). Based on our results, the conclusion that Actinobacteria and Acidobacteria were sensitive toward the macrolactin can be safely drawn.

On the other hand, the relative abundance of Proteobacteria (Beta-proteobacteria and Gamma-proteobacteria, Supplementary 
TABLE 3 | Real-time PCR quantification of 16S rRNA gene and PKS gene.

\begin{tabular}{lcc}
\hline & $\begin{array}{c}\text { 16S rRNA } \log _{10} \\
\text { (copy number)/g dry soil }\end{array}$ & $\begin{array}{c}\text { PKS } \log _{\mathbf{1 0}} \text { (copy number)/g } \\
\text { dry soil }\end{array}$ \\
\hline Macrolactin & $8.81 \pm 0.22 \mathrm{a}$ & $7.32 \pm 0.10 \mathrm{~b}$ \\
Water & $9.01 \pm 0.11 \mathrm{a}$ & $7.63 \pm 0.21 \mathrm{a}$
\end{tabular}

The copy number of genes in $1 \mathrm{~g}$ dry soil was estimated based on the results of real-time PCR. The different letters " $a$ " and " $b$ " here used for the marker of statistically significant difference $(p<0.05)$, if there is significant difference between macrolactin treatment and water control, they are marked as "a" and "b" separately, if not, they are both marked as "a". Each sample was measured in triplicate, and data show a mean $\pm S D(n=9)$.

Table S2) and Firmicutes was significantly increased by the addition of macrolactins. These phyla have been reported to be more stable and resistant than other phyla when faced with changes of environmental factors (Barnard et al., 2013).
Further, many species of Firmicutes are macrolactins producer such as Bacillus, that are resistant to macrolactins and elevate in relative abundance by their products (Yuan et al., 2012a). In the previous studies, the abundance of Beta-proteobacteria and Gamma-proteobacteriaalso showed a positive correlation with agricultural chemicals such as glyphosate, atrazine, permethrin and DDT as they were able to degrade these chemicals (Lew et al., 2013; Muturi et al., 2013). Beta-proteobacteria and Gamma-proteobacteria might be responsible for degradation of macrolactins in soil. The results of this study showed a decrease in the copy number of PKS synthase gene after the application of macrolactins. Other than Bacillus species, there are many soil microbes such as such as Actinomyces that contain gene encoding PKS synthase or similar genes (Ayuso-Sacido and Genilloud, 2005). In this study, Actinobacteria were significantly decreased in relative abundance by the application of macrolactins. This

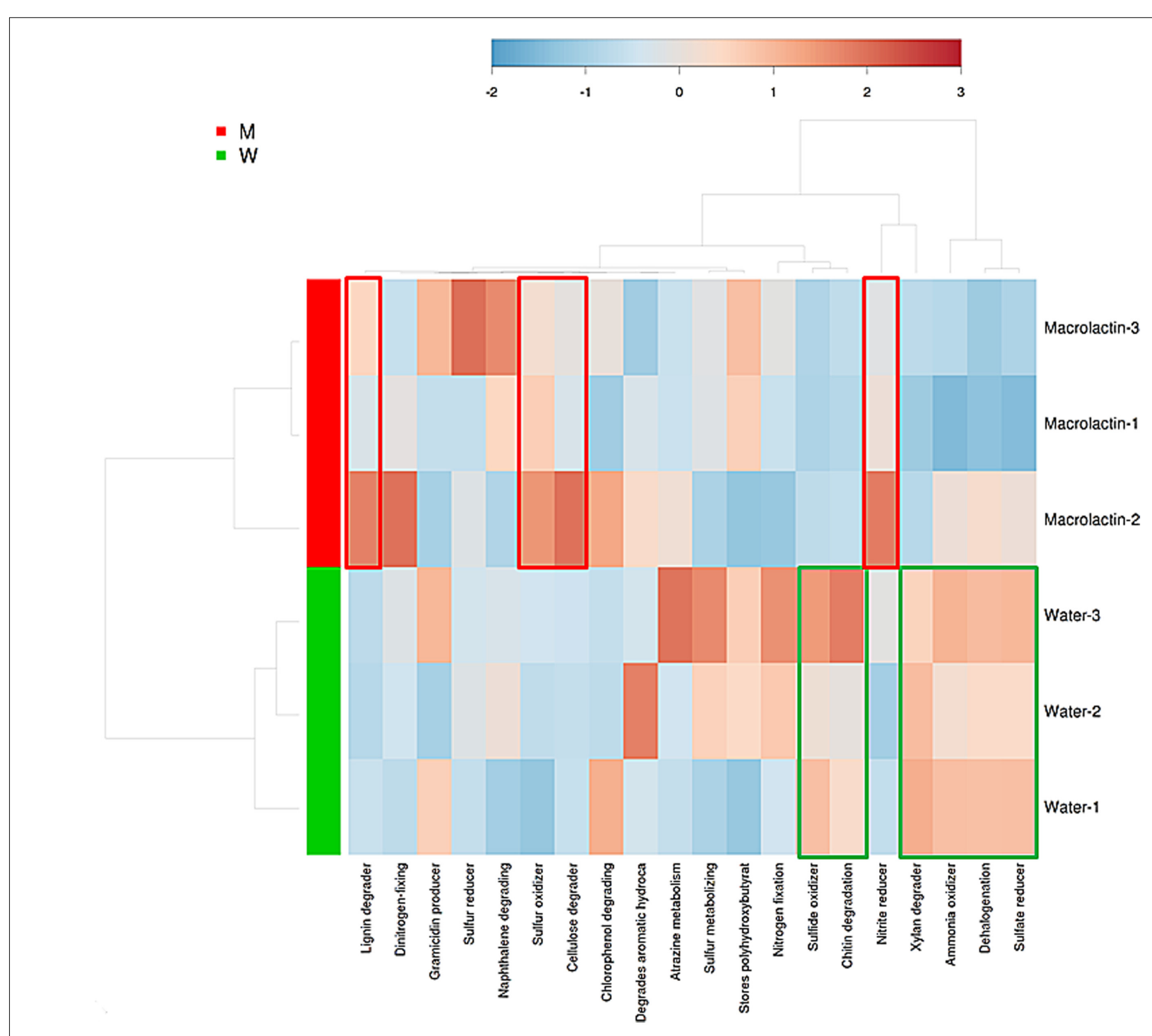

FIGURE 3 | Heatmap analysis of taxonomic to phenotypic mapping of the 16S rRNA sequenced genes between macrolactin treated soil and water control soil generated using METAGENassist. 
could be one reason that macrolactins applied to the soil reduced the relative amount of genotype known to encode PKS synthase.

At the genus level, among the 12 bacterial genera with over $1 \%$ relative abundance, the presence of 9 genera was reduced when exposed to macrolactins, which showed boardspectrum antibacterial activity of macrolactin on the bacteria. However, the relative abundance of the genera Burkholderia, Dyella, and Rhodanobacter was significantly increased (Table 1) which indicated that those groups were more resistant than others when exposed to macrolactin. These genera have been reported to play an important role in degradation of refractory pollutants especially agricultural chemical pesticides. Burkholderia displayed the ability to degrade organophosphorus pesticides in soil (Kikuchi et al., 2012; Pandey et al., 2012; Werren, 2012; Min et al., 2014). Dyella was a genus capable of degrading fenitrothion (Campisano et al., 2014; Itoh et al., 2014). The genus Rhodanobacter was able to remove benzo( $\alpha$ )pyrene and anilofos from the environment (Kanaly et al., 2002; Zhang et al., 2011).

The predicted soil bacterial functions, matched well with the soil bacterial community, were explored using METAGENassist which is a tool to predict the potential functions of the soil bacterial community, just as PICRUSt (Langille et al., 2013). It would have been better if the functional analysis had been done based on transcriptomic data. Current method monitors environmental DNA to predict microbial functions such as Geo-Chip, which could have given the relative abundance of distinct functional genes to predict the microbial functions in the habitat (He et al., 2007). For example, there were several species of Rhodanobacter found to be denitrifiers (van den Heuvel et al., 2010; Green et al., 2012), which might explain the significantly increased abundance of nitrite reducing metabolism (Figure 3). Here, we collected macrolactin compounds and evaluated their effects on the soil bacterial community. The results showed that the bacterial community diversity and the relative abundance of most taxa were decreased by the application of macrolactins. The increased relative abundance of Proteobacteria especially the taxa Burkholderia, Dyella, and

\section{REFERENCES}

Arguelles-Arias, A., Ongena, M., Halimi, B., Lara, Y., Brans, A., Joris, B., et al. (2009). Bacillus amyloliquefaciens GA1 as a source of potent antibiotics and other secondary metabolites for biocontrol of plant pathogens. Microb. Cell Fact. 8:63. doi: 10.1186/1475-2859-8-63

Arndt, D., Xia, J., Liu, Y., Zhou, Y., Guo, A. C., Cruz, J. A., et al. (2012). METAGENassist: a comprehensive web server for comparative metagenomics. Nucleic Acids Res. 40, W88-W95. doi: 10.1093/nar/gks497

Ayuso-Sacido, A., and Genilloud, O. (2005). New PCR primers for the screening of NRPS and PKS-I systems in actinomycetes: detection and distribution of these biosynthetic gene sequences in major taxonomic groups. Microb. Ecol. 49, 10-24. doi: 10.1007/s00248-004-0249-6

Barnard, R. L., Osborne, C. A., and Firestone, M. K. (2013). Responses of soil bacterial and fungal communities to extreme desiccation and rewetting. ISME J. 7, 2229-2241. doi: 10.1038/ismej.2013.104

Barros, N., and Feijóo, S. (2003). A combined mass and energy balance to provide bioindicators of soil microbiological quality. Biophys. Chem. 104, 561-572. doi: 10.1016/S0301-4622(03)00059-0

Bentley, S. D., Chater, K. F., Cerdeño-Tárraga, A. M., Challis, G. L., Thomson, N. R., James, K. D., et al. (2002). Complete genome sequence of the model
Rhodanobacter might be due to higher resistance to macrolactins while Acidobacteria were sensitive to macrolactins in the soil. In addition, the abundance of genes encoding proteins responsible for antibiotic production (PKS gene) in soil could be reduced by the application of the microbial antibiotic (macrolactin). This study showed that microbial source antibiotics can change the bacterial community as agricultural chemicals do. However, it should be determined that how long it takes until macrolactins are totally degraded, and how long the effect on the bacterial community lasts to better manipulate soil microbial flora in the future.

\section{AUTHOR CONTRIBUTIONS}

JY and MZ: conducted all experiments, conceived the study, and wrote the paper; JY and RL: analyzed the data; QS, conceived the study, supervised the study, and wrote the paper; CR, WR, and $\mathrm{QH}$ : provided critical comments on the study, and helped write the paper.

\section{ACKNOWLEDGMENT}

This study was financially supported by China Science and Technology Ministry (973 Program, 2015CB150506), National Nature Science Foundation of China (31330069), and Jiangsu Science and Technology Department (BK20150059). JY was supported by National Postdoctoral Program for Innovative Talents (BX201600075).

\section{SUPPLEMENTARY MATERIAL}

The Supplementary Material for this article can be found online at: http://journal.frontiersin.org/article/10.3389/fmicb. 2016.01904/full\#supplementary-material

actinomycete Streptomyces coelicolor A3(2). Nature 417, 141-147. doi: 10.1038/ 417141a

Bremner, J. M., and Blackmer, A. M. (1978). Nitrous oxide: emission from soils during nitrification of fertilizer nitrogen. Science 199, 295-296. doi: 10.1126/ science.199.4326.295

Campisano, A., Antonielli, L., Pancher, M., Yousaf, S., Pindo, M., and Pertot, I. (2014). Bacterial endophytic communities in the grapevine depend on pest management. PLoS ONE 9:e112763. doi: 10.1371/journal.pone.0112763

Chen, X. H., Koumoutsi, A., Scholz, R., Schneider, K., Vater, J., Sussmuth, R., et al. (2009). Genome analysis of Bacillus amyloliquefaciens FZB42 reveals its potential for biocontrol of plant pathogens. J. Biotechnol. 140, 27-37. doi: 10. 1016/j.jbiotec.2008.10.011

Edgar, R. C., Haas, B. J., Clemente, J. C., Quince, C., and Knight, R. (2011). UCHIME improves sensitivity and speed of chimera detection. Bioinformatics 27, 2194-2200. doi: 10.1093/bioinformatics/btr381

Fierer, N., Leff, J. W., Adams, B. J., Nielsen, U. N., Bates, S. T., Lauber, C. L., et al. (2012). Cross-biome metagenomic analyses of soil microbial communities and their functional attributes. Proc. Natl. Acad. Sci. U.S.A. 109, 21390-21395. doi: $10.1073 /$ pnas. 1215210110

Floch, C., Chevremont, A.-C., Joanico, K., Capowiez, Y., and Criquet, S. (2011). Indicators of pesticide contamination: soil enzyme compared to functional 
diversity of bacterial communities via Biolog ${ }^{\circledR}$ Ecoplates. Eur. J. Soil Biol. 47, 256-263. doi: 10.1016/j.ejsobi.2011.05.007

Garson, M. J. (1993). The biosynthesis of marine natural products. Chem. Rev. 93 , 1699-1733. doi: 10.1021/cr00021a003

Green, S. J., Prakash, O., Jasrotia, P., Overholt, W. A., Cardenas, E., Hubbard, D., et al. (2012). Denitrifying bacteria from the genus Rhodanobacter dominate bacterial communities in the highly contaminated subsurface of a nuclear legacy waste site. Appl. Environ. Microbiol. 78, 1039-1047. doi: 10.1128/AEM. 06435-11

Gustafson, K., Roman, M., and Fenical, W. (1989). The macrolactins, a novel class of antiviral and cytotoxic macrolides from a deep-sea marine bacterium. J. Am. Chem. Soc. 111, 7519-7524. doi: 10.1021/ja00201a036

Halling-Sørensen, B., Sengeløv, G., and Tjørnelund, J. (2002). Toxicity of tetracyclines and tetracycline degradation products to environmentally relevant bacteria, including selected tetracycline-resistant bacteria. Arch. Environ. Contam. Toxicol. 42, 263-271. doi: 10.1007/s00244-001-0017-2

Han, J. S., Cheng, J. H., Yoon, T. M., Song, J., Rajkarnikar, A., Kim, W. G., et al. (2005). Biological control agent of common scab disease by antagonistic strain Bacillus sp. sunhua. J. Appl. Microbiol. 99, 213-221. doi: 10.1111/j.1365-2672. 2005.02614.x

He, S., Wang, H., Wu, B., Zhou, H., Zhu, P., Yang, R., et al. (2012). Response surface methodology optimization of fermentation conditions for rapid and efficient accumulation of macrolactin A by marine Bacillus amyloliquefaciens ESB-2. Molecules 18, 408-417. doi: 10.3390/molecules 18010408

He, S., Wang, H., Yan, X., Zhu, P., Chen, J., and Yang, R. (2013). Preparative isolation and purification of macrolactin antibiotics from marine bacterium Bacillus amyloliquefaciens using high-speed counter-current chromatography in stepwise elution mode. J. Chromatogr. A 1272, 15-19. doi: 10.1016/j.chroma. 2012.11.029

He, Z., Gentry, T. J., Schadt, C. W., Wu, L., Liebich, J., Chong, S. C., et al. (2007). GeoChip: a comprehensive microarray for investigating biogeochemical, ecological and environmental processes. ISME J. 1, 67-77. doi: 10.1038/ismej. 2007.2

Itoh, H., Navarro, R., Takeshita, K., Tago, K., Hayatsu, M., Hori, T., et al. (2014). Bacterial population succession and adaptation affected by insecticide application and soil spraying history. Front. Microbiol. 5:457. doi: 10.3389/ fmicb.2014.00457

Jacobsen, C. S., and Hjelmsø, M. H. (2014). Agricultural soils, pesticides and microbial diversity. Curr. Opin. Biotechnol. 27, 15-20. doi: 10.1016/j.copbio. 2013.09.003

Jaruchoktaweechai, C., Suwanborirux, K., Tanasupawatt, S., Kittakoop, P., and Menasveta, P. (2000). New macrolactins from a marine Bacillus sp Sc026. J. Nat. Prod. 63, 984-986. doi: 10.1021/np990605c

Kanaly, R. A., Harayama, S., and Watanabe, K. (2002). Rhodanobacter sp. strain BPC1 in a benzo[a]pyrene-mineralizing bacterial consortium. Appl. Environ. Microbiol. 68, 5826-5833. doi: 10.1128/AEM.68.12.5826-5833.2002

Kanoh, S., and Rubin, B. K. (2010). Mechanisms of action and clinical application of macrolides as immunomodulatory medications. Clin. Microbiol. Rev. 23, 590-615. doi: 10.1128/CMR.00078-09

Kikuchi, Y., Hayatsu, M., Hosokawa, T., Nagayama, A., Tago, K., and Fukatsu, T. (2012). Symbiont-mediated insecticide resistance. Proc. Natl. Acad. Sci. U.S.A. 109, 8618-8622. doi: 10.1073/pnas.1200231109

Kozich, J., Westcott, S., Baxter, N., Highlander, S., and Schloss, P. (2013). Development of a dual-index sequencing strategy and curation pipeline for analyzing amplicon sequence data on the MiSeq Illumina Sequencing Platform. Appl. Environ. Microbiol. 79, 5112-5120. doi: 10.1128/AEM. 01043-13

Langille, M. G., Zaneveld, J., Caporaso, J. G., McDonald, D., Knights, D., Reyes, J. A., et al. (2013). Predictive functional profiling of microbial communities using $16 \mathrm{~S}$ rRNA marker gene sequences. Nat. Biotechnol. 31, 814-821. doi: $10.1038 /$ nbt. 2676

Lew, S., Lew, M., Biedunkiewicz, A., and Szarek, J. (2013). Impact of pesticide contamination on aquatic microorganism populations in the littoral zone. Arch. Environ. Contam. Toxicol. 64, 399-409. doi: 10.1007/s00244-0129852-6

Lewis, D. L., Garrison, A. W., Wommack, K. E., Whittemore, A., Steudler, P., and Melillo, J. (1999). Influence of environmental changes on degradation of chiral pollutants in soils. Nature 401, 898-901. doi: 10.1038/44801
Marino, J. P., McClure, M. S., Holub, D. P., Comasseto, J. V., and Tucci, F. C. (2002). Stereocontrolled synthesis of (-)-macrolactin A. J. Am. Chem. Soc. 124, 1664-1668. doi: 10.1021/ja017177t

Mendes, R., Kruijt, M., de Bruijn, I., Dekkers, E., van der Voort, M., Schneider, J. H. M., et al. (2011). Deciphering the rhizosphere microbiome for diseasesuppressive bacteria. Science 332, 1097-1100. doi: 10.1126/science.1203980

Min, J., Zhang, J. J., and Zhou, N. Y. (2014). The gene cluster for paranitrophenol catabolism is responsible for 2-chloro-4-nitrophenol degradation in Burkholderia sp. strain SJ98. Appl. Environ. Microbiol. 80, 6212-6222. doi: 10.1128/AEM.02093-14

Monard, C., Vandenkoornhuyse, P., Le Bot, B., and Binet, F. (2011). Relationship between bacterial diversity and function under biotic control: the soil pesticide degraders as a case study. ISME J. 5, 1048-1056. doi: 10.1038/ismej.2010.194

Muñoz-Leoz, B., Ruiz-Romera, E., Antigüedad, I., and Garbisu, C. (2011). Tebuconazole application decreases soil microbial biomass and activity. Soil Biol. Biochem. 43, 2176-2183. doi: 10.1016/j.soilbio.2011.07.001

Muturi, E. J., Orindi, B. O., and Kim, C. H. (2013). Effect of leaf type and pesticide exposure on abundance of bacterial taxa in mosquito larval habitats. PLoS ONE 8:e71812. doi: 10.1371/journal.pone.0071812

Negreanu, Y., Pasternak, Z., Jurkevitch, E., and Cytryn, E. (2012). Impact of treated wastewater irrigation on antibiotic resistance in agricultural soils. Environ. Sci. Technol. 46, 4800-4808. doi: 10.1021/es204665b

Newman, D. J., and Cragg, G. M. (2012). Natural products as sources of new drugs over the 30 years from 1981 to 2010. J. Nat. Prod. 75, 311-335. doi: $10.1021 / \mathrm{np} 200906 \mathrm{~s}$

Owen, J. G., Reddy, B. V., Ternei, M. A., Charlop-Powers, Z., Calle, P. Y., Kim, J. H., et al. (2013). Mapping gene clusters within arrayed metagenomic libraries to expand the structural diversity of biomedically relevant natural products. Proc. Natl. Acad. Sci. U.S.A. 110, 11797-11802. doi: 10.1073/pnas.1222159110

Pandey, J., Sharma, N. K., Khan, F., Ghosh, A., Oakeshott, J. G., Jain, R. K., et al. (2012). Chemotaxis of Burkholderia sp. strain SJ98 towards chloronitroaromatic compounds that it can metabolise. BMC Microbiol. 12:19. doi: 10.1186/14712180-12-19

Park, S., Regmi, S. C., Park, S. Y., Lee, E. K., Chang, J. H., Ku, S. K., et al. (2014). Protective effect of 7-O-succinyl macrolactin A against intestinal inflammation is mediated through PI3-kinase/Akt/mTOR and NF-kB signaling pathways. Eur. J. Pharmacol. 735, 184-192. doi: 10.1016/j.ejphar.2014.04.024

Pruesse, E., Quast, C., Knittel, K., Fuchs, B. M., Ludwig, W., Peplies, J., et al. (2007). SILVA: a comprehensive online resource for quality checked and aligned ribosomal RNA sequence data compatible with ARB. Nucleic Acids Res. 35, 7188-7196. doi: $10.1093 / \mathrm{nar} / \mathrm{gkm} 864$

Reichel, R., Radl, V., Rosendahl, I., Albert, A., Amelung, W., Schloter, M., et al. (2014). Soil microbial community responses to antibiotic-contaminated manure under different soil moisture regimes. Appl. Microbiol. Biotechnol. 98, 6487-6495. doi: 10.1007/s00253-014-5717-4

Romero-Tabarez, M., Jansen, R., Sylla, M., Lunsdorf, H., Haussler, S., Santosa, D. A., et al. (2006). 7-O-malonyl macrolactin A, a new macrolactin antibiotic from Bacillus subtilis active against methicillin-resistant Staphylococcus aureus, vancomycin-resistant enterococci, and a small-colony variant of Burkholderia cepacia. Antimicrob. Agents Chemother. 50, 1701-1709. doi: 10.1128/AAC.50.5. 1701-1709.2006

Schloss, P. D., Westcott, S. L., Ryabin, T., Hall, J. R., Hartmann, M., Hollister, E. B., et al. (2009). Introducing mothur: open-source, platform-independent, community-supported software for describing and comparing microbial communities. Appl. Environ. Microbiol. 75, 7537-7541. doi: 10.1128/AEM. 01541-09

Schmitt, H., van Beelen, P., Tolls, J., and van Leeuwen, C. L. (2004). Pollutioninduced community tolerance of soil microbial communities caused by the antibiotic sulfachloropyridazine. Environ. Sci. Technol. 38, 1148-1153. doi: 10. 1021/es034685p

Schneider, K., Chen, X. H., Vater, J., Franke, P., Nicholson, G., Borriss, R., et al. (2007). Macrolactin is the polyketide biosynthesis product of the pks2 cluster of Bacillus amyloliquefaciens FZB42. J. Nat. Prod. 70, 1417-1423. doi: 10.1021/ np070070k

Smith, A. B., and Ott, G. R. (1996). Total synthesis of (-)-macrolactin A. J. Am. Chem. Soc. 118, 13095-13096. doi: 10.1021/ja963543a

Sopheareth, M., Chan, S., Naing, K. W., Lee, Y. S., Hyun, H. N., Kim, Y. C., et al. (2013). Biocontrol of late blight (Phytophthora capsici) disease and growth 
promotion of pepper by Burkholderia cepacia MPC-7. Plant Pathol. J. 29, 67-76. doi: 10.5423/PPJ.OA.07.2012.0114

Thiele-Bruhn, S., Seibicke, T., Schulten, H. R., and Leinweber, P. (2004). Sorption of sulfonamide pharmaceutical antibiotics on whole soils and particle-size fractions. J. Environ. Qual. 33, 1331-1342. doi: 10.2134/jeq2004.1331

Torsvik, V., Goksøyr, J., and Daae, F. L. (1990). High diversity in DNA of soil bacteria. Appl. Environ. Microbiol. 56, 782-787.

Udikovic-Kolic, N., Wichmann, F., Broderick, N. A., and Handelsman, J. (2014). Bloom of resident antibiotic-resistant bacteria in soil following manure fertilization. Proc. Natl. Acad. Sci. U.S.A. 111, 15202-15207. doi: 10.1073/pnas. 1409836111

van den Heuvel, R. N., van der Biezen, E., Jetten, M. S., Hefting, M. M., and Kartal, B. (2010). Denitrification at $\mathrm{pH} 4$ by a soil-derived Rhodanobacterdominated community. Environ. Microbiol. 12, 3264-3271. doi: 10.1111/j.14622920.2010.02301.x

Wang, Q., Garrity, G. M., Tiedje, J. M., and Cole, J. R. (2007). Naive Bayesian classifier for rapid assignment of rRNA sequences into the new bacterial taxonomy. Appl. Environ. Microbiol. 73, 5261-5267. doi: 10.1128/AEM.000 62-07

Wang, X., Luo, C., and Chen, Z. (2012). Genome sequence of the plant growthpromoting rhizobacterium Bacillus sp. strain 916. J. Bacteriol. 194, 5467-5468. doi: 10.1128/JB.01266-12

Werren, J. H. (2012). Symbionts provide pesticide detoxification. Proc. Natl. Acad. Sci. U.S.A. 109, 8364-8365. doi: 10.1073/pnas. 1206194109

Yamamura, S., Watanabe, K., Suda, W., Tsuboi, S., and Watanabe, M. (2014). Effect of antibiotics on redox transformations of arsenic and diversity of arseniteoxidizing bacteria in sediment microbial communities. Environ. Sci. Technol. 48, 350-357. doi: 10.1021/es403971s

Yuan, J., Li, B., Zhang, N., Waseem, R., Shen, Q., and Huang, Q. (2012a). Production of bacillomycin- and macrolactin-type antibiotics by Bacillus amyloliquefaciens NJN-6 for suppressing soilborne plant pathogens. J. Agric. Food Chem. 60, 2976-2981. doi: 10.1021/jf204868z

Yuan, J., Raza, W., Huang, Q., and Shen, Q. (2012b). The ultrasound-assisted extraction and identification of antifungal substances from B. amyloliquefaciens strain NJN-6 suppressing Fusarium oxysporum. J. Basic Microbiol. 52, 721-730. doi: $10.1002 / j o b m .201100560$

Yuan, J., Ruan, Y., Wang, B., Zhang, J., Waseem, R., Huang, Q., et al. (2013). Plant growth-promoting rhizobacteria strain Bacillus amyloliquefaciens NJN6-enriched bio-organic fertilizer suppressed Fusarium wilt and promoted the growth of banana plants. J. Agric. Food Chem. 61, 3774-3780. doi: 10.1021/ jf $400038 \mathrm{z}$

Yuan, J., Zhang, F., Wu, Y., Zhang, J., Raza, W., Shen, Q., et al. (2014). Recovery of several cell pellet-associated antibiotics produced by Bacillus amyloliquefaciens NJN-6. Lett. Appl. Microbiol. 59, 169-176. doi: 10.1111/lam. 12260

Zhang, J., Zheng, J. W., Hang, B. J., Ni, Y. Y., He, J., and Li, S. P. (2011). Rhodanobacter xiangquanii sp. nov., a novel anilofos-degrading bacterium isolated from a wastewater treating system. Curr. Microbiol. 62, 645-649. doi: 10.1007/s00284-010-9757-4

Zotchev, S. B., Sergeyko, A. P., Sobolev, B. N., Filimonov, D., and Poroikov, V. (2006). Rational design of macrolides by virtual screening of combinatorial libraries generated through in silico manipulation of polyketide synthases. J. Med. Chem. 49, 2077-2087. doi: 10.1021/jm051035i

Zviagintsev, D. G., Zenova, G. M., Doroshenko, E. A., Griadunova, A. A., Gracheva, T. A., and Sudnitsyn, I. I. (2007). [Actinomycete growth in conditions of low moisture]. Izv. Akad. Nauk. Ser. Biol. 3, 296-302.

Conflict of Interest Statement: The authors declare that the research was conducted in the absence of any commercial or financial relationships that could be construed as a potential conflict of interest.

Copyright (c) 2016 Yuan, Zhao, Li, Huang, Rensing, Raza and Shen. This is an open-access article distributed under the terms of the Creative Commons Attribution License (CC BY). The use, distribution or reproduction in other forums is permitted, provided the original author(s) or licensor are credited and that the original publication in this journal is cited, in accordance with accepted academic practice. No use, distribution or reproduction is permitted which does not comply with these terms. 